Syntax Literate: Jurnal Ilmiah Indonesia p-ISSN: 2541-0849

e-ISSN: 2548-1398

Vol. 6, No. 7, Juli 2021

\title{
FAKTOR-FAKTOR ANTESEDEN PERUBAHAN ORGANISASI PADA PERUSAHAAN MULTINASIONAL
}

\section{Yuanti Adi Hutami, Mirwan Surya Perdhana}

Universitas Diponegoro (UNDIP) Semarang, Jawa Tengah, Indonesia

Email: yuantihtm800@gmail.com, mirwan@live.undip.ac.id

\begin{abstract}
Abstrak
Kepemimpinan lintas budaya yang kompleks, perubahan lingkungan dan ketidakpastian merupakan tantangan bagi pemimpin perusahaan multinasional. Penelitian ini bertujuan melihat faktor yang mempengaruhi keberhasilan perubahan organisasi di perusahaan multinasional. Pemimpin ekspatriat sebagai top manajemen berperan sangat penting dalam perubahan. Tindakan top manajemen dalam membangun mental perubahan, penyampaian visi misi secara jelas, upaya keterbukaan komunikasi dengan manajemen lokal dapat mendukung keberhasilan perubahan. Penelitian ini menggunakan metode kajian pustaka dengan analisis deskriptif, dan dapat ditingkatkan dalam penelitian empiris untuk menguji temuan. Hasil penelitian ini menunjukkan faktor yang memberikan kontribusi keberhasilan perubahan adalah komunikasi dalam unit organisasi, keterlibatan dari semua komponen termasuk peran top manajemen yang melakukan pesan berulang untuk mengkomunikasikan perubahan. Namun dalam praktik manajemen multinasional masih ditemukan dalam proses pengambilan keputusan penting pembicaraan terbatas dikalangan ekspatriat, tidak melibatkan banyak pihak dan tertutup. Penelitian ini memperkuat bahwa keberhasilan host country diukur dari seberapa besar manajemen Jepang digunakan sebagai budaya organisasi. Faktor kepercayaan yang kuat terhadap pemimpin lokal, peningkatan kompetensi melalui transfer pengetahuan (know how) dari parent company ke host country sebagai strategi perubahan yang tepat.
\end{abstract}

Kata Kunci: kepemimpinan; budaya perusahaan; manajemen pengetahuan

\section{Abstract}

A complex cross-cultural leader, environmental change and yet to be presented to a company of leaders who are berkutao. This research factored in looking at which factors the organization changes in the company. Expatriate leaders over management are crucial in change. Top management's work in building mental change, vision of any mission vision, communication efforts with local management can be a change. This research is a method of literature study with descriptive analysis, and high in empirical research to test the findings. The results of this study are factors in which the style of change is safe in organizational units, the function of all component roles over management that message messages repeat to communicate change. But in the practice of management management is still good in the process of important decisions limited among expatriates, there are not many

$\begin{array}{ll}\text { How to cite: } & \text { Hutami, Yuanti Adi dan Mirwan Surya Perdhana (2021) Faktor-Faktor Anteseden Perubahan } \\ & \text { Organisasi pada Perusahaan Multinasional. Syntax Literate: Jurnal Ilmiah Indonesia. 6(7). } \\ & \text { http://dx.doi.org/10.36418/ syntax-literate.v6i7.3604 } \\ \text { E-ISSN: } & \text { 2548-1398 } \\ \text { Published by: } & \text { Ridwan Institute }\end{array}$


parties and closed. The study dried up, bamboo host country of how big Japan's management times cultural organizations. A strong factor against local leaders, improved performance through news (know how) from parent company to country host as the right change strategy.

Keywords: leadership; corporate culture; knowledge management

\section{Pendahuluan}

Dinamika bisnis dalam konteks global menarik sebagai pembahasan praktek pengelolaan organisasi dalam studi sumber daya manusia internasional. Perusahaan multinasional melakukan bentuk kerjasama global dalam bentuk join venture, yang memunculkan istilah perusahaan induk (parent company) dan negara tuan rumah sebagai tujuan bisnis (host country) (Geringer \& Hebert, 1989). Konsekuensi pertemuan antar budaya dari nilai yang dianut muncul dalam kerjasama di perusahaan multinasional.

Tantangan globalisasi menuntut para pimpinan di perusahaan multinasional mempunyai pola pikir global dan mampu bertindak dengan kearifan lokal. Keberhasilan perusahaan multinasional Jepang di negara host country dapat dilihat dari seberapa besar menerima dan beradaptasi dengan metode manajemen Jepang menjadi suatu budaya organisasi (Ashta, Stokes, \& Hughes, 2018).

Peran perusahaan multinasional merupakan pemain utama dalam ekonomi global, dalam perspektif pengetahuan maupun jaringan (networking) dapat diketahui bahwa kemampuan dalam kemampuan dalam mentransfer pengetahuan merupakan keunggulan bersaing. Keunggulan dalam hubungan antar negara dalam waktu jangka panjang dapat menciptakan pengetahuan dan pengalaman baru yang bersifat tacit sehingga akan sulit ditiru.

Tantangan untuk mampu beradaptasi terhadap perubahan menjadi masalah yang harus diterima oleh pemimpin perusahaan multinasional. Studi pustaka menjelaskan peran dari pimpinan untuk keberhasilan perubahan sangat penting karena perubahan organisasi tidak selalu berhasil, menurut hasil penelitian $70 \%$ perubahan organisasi tidak berhasil (Hughes, 2011). Tingkat keberhasilan yang buruk ini mengindikasikan hal yang mendasar yaitu kerangka kerja dalam penerapan dan pengelolaan perubahan dalam suatu organisasi belum valid.

Perubahan sebagai elemen penting yang mengukur capabilities dan culture yang bertujuan untuk penyelarasan organisasi. Karena laju perubahan organisasi tidak lebih besar dari perubahan lingkungan bisnis yang terjadi, maka mentalitas dasar, perilaku organisasi, etika bisnis, etika kerja, pengetahuan dan ketrampilan termasuk kepemimpinan dibentuk sesuai dengan tuntutan organisasi.

Perubahan dalam perusahaan multinasional dapat dalam proses manajemen melalui global integration dan local differentiation (Pesalj, 2011). Tipe perusahaan membentuk network dalam menfasilitasi pengetahuan antar unit yang tergabung. Karakteristik perusahaan sebagai entitas aktif dalam meningkatkan kapasitas dan kemampuan pengetahuan baru dapat disebut sebagai ciri keunggulan bersaing (Krogh, 
Nonaka, \& Aben, 2001). Penghambat transformasi organisasi disebabkan kualitas kerja rendah. Faktor yang berpengaruh dalam perubahan organisasi yaitu pendidikan, kemampuan bahasa asing rendah, intensitas komunikasi kurang, keterbatasan waktu untuk penyebaran informasi (Bojesson \& Fundin, 2020).

Perusahaan multinasional dengan pemimpin ekspatriat perlu menyesuaikan gaya kepemimpinannya dengan manager dan karyawan lokal, karena pemimpin asing dipastikan mempunyai gaya kepemimpinan berbeda dengan lokal (Artina, Desnasari, Fitriyah, \& Rizkita, 2020). Kepemimpinan merupakan kemampuan yang dimiliki individu dalam memotivasi, mempimpin dan memberi pengaruh orang lain agar berperan dalam mencapai tujuan organisasi. Kesuksesasan organisasi ditentukan salah satunya dari peran pemimpin (Javidan \& Teagarden, 2011).

Menurut (Javidan \& Teagarden, 2011), definisi pola pikir global adalah ketersediaan pengetahuan, kognitif, dan atribut psikologis yang memungkinkan pemimpin global untuk memengaruhi individu, kelompok, dan organisasi (tidak ada batas organisasi global) mewakili beragam budaya atau politik atau sistem kelembagaan untuk berkontribusi terhadap pencapaian tujuan organisasi global

Keberhasilan pemimpin global dipengaruhi oleh pola pikir global yang secara teori yang dibangun dari 3 komponen:

1. Intelectual Capital, menunjukan tingkat intektual dari pemimpin dan kapasitas kognitif dari beberapa indikator pengetahuan industri global, pemahaman nilai jaringan dan organisasi dan memiliki daya serap terhadap budaya.

2. Social Capital, menunjukan hubungan baik didalam dan diluar oleh perusahaan, dilihat dari jaringan internasional, kemampuan interpersonal dalam membangun hubungan baru, dan keterampilan sebagai pemimpin yang mampu menggerakan karyawan ke tingkat global.

3. Psychological Capital, menunjukan profil psikologis yang positif, kosmopolitanisme dan hasrat untuk pertemuan lintas budaya dari beberapa atribut: respek terhadap budaya yang berbeda.

Dominasi top manajemen ekspatriat memainkan peran dalam merespon perubahan bertujuan agar organisasi berkembang dan bertahan dalam bisnis (Manning, Shacklock, Bell, \& Manning, 2012). Pentingnya perubahan organisasi, maka keterampilan manajerial dari pimpinan sangat dibutuhkan. Kemampuan pemimpin yang handal dapat ditingkatkan salah satunya dengan rotasi dalam struktur organisasi, menciptakan budaya pembelajaran di level pemimpin.

Kompleksitas struktur organisasi dan proses manajemen perusahaan multinasional, upaya peningkatan keunggulan bersaing dapat dilakukan melalui integrasi global dan local differentiation (Pesalj, 2011). Proses inovasi tidak berfokus ke parent company namun disebarkan kepada host country melalui sistem. Keunggulan bersaing mengarah pada karakteristik perusahaan sebagai entitas aktif dalam meningkatkan kapasitas dan kemampuan pengetahuan baru (Von Krogh et al., 2001).

Penelitian lain menunjukan berbagai pengetahuan dapat meningkatkan kemampuan dinamis organisasi yang merupakan faktor pendorong terhadap kinerja 
perusahaan multinasional di Korea (Chang, Yan, \& Tseng, 2012). Dari beberapa penelitian menyimpulan bahwa dengan berbagi pengetahuan antar unit perusahaan dapat berpengaruh positif terhadap kinerja perusahaan multinasional. Namun pendapat yang berbeda dari penelitian lain terdapat pendapat kontradiktif (Qin, Ramburuth, \& Wang, 2011) yang mengindikasikan pengaruh negatif jarak budaya terhadap pengetahuan baru dalam organisasi.

Penelitian dari (Lucas, 2006), menyampaikan peran penting dari manager agar konsisten mengikuti berbagi pengetahuan walaupun ada dukungan dari perusahaan induk, namun resistensi perubahan masih ada dan mekanisme sharing perlu dikontrol. Keberhasilan berbagi pengetahuan akan tercipta dalam budaya yang selaras.

Pemimpin dari jajaran ekspatriat bertindak sebagai penjaga gerbang yang melintasi kesenjangan lintas budaya antara kantor pusat dan anak perusahaan, menggunakan Culture Quaotation (CQ) mereka sebagai filter dalam proses transfer pengetahuan (Vlajčić, Caputo, Marzi, \& Dabić, 2019).

Gaya kepemimpinan pada manajer ekspatriat senior telah menunjukkan bahwa Culture Quotation (CQ) metakognitif dan motivasi tampaknya menjadi faktor penting dalam meningkatkan efektivitas kemampuan pemimpin ekspatriat senior. Mereka memberikan contoh kepada pengikut mereka melalui kegiatan yang konsisten dengan nilai-nilai budaya mereka, mengembangkan kolaborasi dan membangun kepercayaan dalam tim (Elenkov \& Manev, 2009).

Penelitian lanjutan oleh (Qin et al., 2011), membangun preposisi berdasarkan dimensi Hofstede yaitu individualism dan collectivism. Menurut (Tietze, 2021), individu dari Asia yang merepresentasikan budaya collectivism lebih peka terhadap pengetahuan tacit namun budaya individualism (Amerika dan Australia) akan berkomunikasi langsung dan eksplisit sehingga lebih peka terhadap pengetahuan eksplisit. Berbagi pengetahuan dilakukan di tingkat individu, secara bersamaan berkembang ke tingkat kelompok dan berakhir di tingkat organisasi (Satsios \& Hadjidakis, 2018). Sumber pengetahuan internal melalui jaringan informal di antara karyawan yang memiliki keahlian (Von Krogh et al., 2001).

Pembelajaran masing-masing individu atau pertukaran pengetahuan secara kolektif, akses pengetahuan dipengaruhi oleh kekuatan proteksi pengetahuan dari perusahaan partner dan tacit knowledge yang dikuasai (Kumar \& Singh, 2020). Kepercayaan menjadi faktor utama aksesbilitas pengetahuan dan mendorong proses tersampaikannya pengetahuan tacit yang melekat keyakinan, nilai personal dan pengalaman dari seseorang (Von Krogh et al., 2001).

Nilai budaya kolektif dapat berperan dalam menentukan seberapa positif individu memberi dukungan organisasi tentang keragaman, proses rekruitmen dan pelatihan yang memperhatikan aspek keragaman (Duncan \& Herrera, 2014). Menurut (Dzunic, Boljanovic, \& Subotic, 2012), faktor yang dapat mempengaruhi keberhasilan berbagi pengetahuan diperusahaan multinasional adalah budaya nasional, bahasa, keragaman tenaga kerja, pola pikir global, budaya organisasi dan struktur jaringan perusahaan. Budaya kolektif berhubungan positif dengan kepemimpinan berorientasi "human". 
Organisasi yang berorientasi kepemimpinan memperhatikan aspek perhatian, sensistivitas, persahabatan dan memberi dukungan bagi orang lain.

Faktor perubahan organisasi merupakan tindakan top manajemen dalam menggerakan adanya perubahan di tingkat manajemen. Budaya baru akan dibentuk dengan perubahan perilaku manusia dalam organisasi. Tujuan dari penelitian ini diharapkan dapat mengetahui faktor-faktor yang berpengaruh dalam keberhasilan perubahan organisasi agar mampu menjawab perubahan capabilitas dan culture organisasi di perusahaan multinasional. Manfaat yang diharapkan dalam penelitian ini adalah dapat memberikan kontribusi dalam mengelola di perusahaan multinasional agar berhasil melakukan perubahan dalam organisasi. Hasil penelitian ini dimungkinkan bisa berbeda secara empiris tergantung dari jenis industri yang akan diteliti dan lokasi negara yang berbeda untuk penelitian.

\section{Metode Penelitian}

Metode penelitian yang digunakan adalah kajian pustaka beberapa artikel jurnal dengan teknik analisis deskriptif. Materi dari penelitian ini mengambil tema perubahan organisasi di perusahaan multinasional di Indonesia.

\section{Hasil dan Pembahasan}

A. Tindakan-tindakan yang dilakukan pemimpin dalam masa perubahan.

1. Kepemimpinan (Leadership)

Manajemen dalam perubahan organisasi merupakan proses yang melibatkan beberapa aspek. Salah satu perubahan yang diminta adalah dari kepemimpinan yang diterapkan baik top manajemen maupun manajemen lini tengah. Kepemimpinan transformasional dapat diukur menjadi 4 dimensi yaitu memberikan pengaruh yang ideal, memotivasi secara inspiratif, memberikan stimulasi intektual dan pemberdayaan.

Peran pimpinan perubahan sebagai elemen penting mempengaruhi organisasi. Laju perubahan organisasi tidak lebih besar dari perubahan lingkungan bisnis yang terjadi. Keberhasilan manajemen perubahan memerlukan skill leadership yang tinggi. Penelitian terdahulu yang meneliti keterkaitan leadership dan perubahan manajemen dilakukan oleh (Mangundjaya, 2013), dengan obyek studi perusahaan konstruksi di Indonesia yang sedang mengalami perubahan organisasi. Hasil penelitian menunjukan bahwa faktor komitmen perubahan dan kesiapan perubahan dari individu berkorelasi positif.

Tindakan yang mendukung perubahan adalah sebagai berikut:

1. Tindakan membangun mental perubahan dengan strategi perubahan organisasi melalui rotasi di jajaran manajemen.

2. Keberhasilan perubahan akan terjadi jika pemimpin yang mempunyai visi yang kuat, jelas dan tahu membawa orang agar sejalan dengan perubahan.

3. Komunikasi yang belum terbuka dari top manajemen dan pemimpin lokal menjadi faktor penghambat implementasi perubahan. 
4. Pemimpin yang bisa menjadi role model, berperilaku yang baik, jujur dan dipercaya.

5. Kemampuan berkomunikasi dari pemimpin yang kuat, menyampaikan pesan perubahan dengan cara yang jelas, dapat memotivasi bawahan dan mempunyai kemampuan mendengar dengan baik.

6. Kemampuan pemimpin yang baik adalah memprioritaskan tugas, menyederhanakan perintah dan mengukur hal apa saja yang mampu untuk dikerjakan bahkan oleh bawahan.

Penelitian di Belanda oleh (de Waal \& Heijtel, 2016) menekankan peran penting intervensi perubahan untuk meningkatkan komitmen bagi manajer dan karyawan dalam mendukung perubahan. Dari 21 kasus menunjukan bahwa $75 \%$ menunjukkan keberhasilan intervensi. Intervensi top manajemen yang berhasil dalam penelitian ini belum dapat dijadikan kesimpulan dengan hasil yang sama, jika terdapat perbedaan jenis industri, obyek penelitian berbeda negara. Peran penting dari leader juga menentukan keberhasilan perubahan.

2. Budaya Perusahaan Yang Mendukung Perubahan

Komunikasi, kolaborasi dan budaya adalah elemen kunci yang harus difokuskan oleh pemimpin baru ketika membuat perubahan (Davis, Kee, \& Newcomer, 2010). Budaya organisasi itu penting karena norma-norma membantu karyawan merasakan sesuatu kenyamanan selama perubahan (Plowman et al., 2007). Pola komunikasi organisasi dipahami dalam kontek budaya, keberhasilan suatu perubahan dimediasi oleh efektivitas komunikasi yang dilakukan oleh pemimpin kepada seluruh komponen organisasi.

Faktor budaya yang mendukung perubahan dapat ditentukan dari:

1. Pemahaman budaya multi kultural dari sikap pimpinan ekpatriat dalam mendukung nilai budaya yang ada dan berusaha menyelaraskan nilai baru dan nilai lama dalam organisasi.

2. Dari pendapat responden top manajemen yang bekerja di negara host country mempunyai kecerdasan budaya multi kultural yang dipersiapkan di negara asal.

3. Intervensi perubahan dalam organisasi terutama untuk menyelaraskan visi dan tindakan dari top manajemen tidak melibatkan banyak pihak, cenderung tertutup, kurang transparan, keputusan penting masih inklusif di bicarakan hanya dari personel ekspatriat.

4. Budaya perubahan yang paling dasar adalah meninggalkan perilaku lama yang tidak sesuai dengan tuntutan organisasi, tidak ada yang salah dalam budaya, namun yang penting adalah menyelaraskan budaya terhadap visi, misi dan strategi bisnis.

5. Budaya berhubungan dengan perilaku dan merupakan hal dinamis dan membutuhkan waktu dan kesiapan dari pengikutnya. Terwujudnya budaya keberlanjutan merupakan tujuan akhir dari perubahan.

Perusahaan multinasional kesuksesan mengelola keragaman adalah tugas penting dari pimpinan. Kepemimpinan dalam studi Geert Hosftede berjudul 
"Cultural Consequence" (1980) menguji perbedaan dan persamaan budaya nasional dari anggota perusahaan multi nasional yang diawakili oleh 140 negara. (Duncan \& Herrera, 2014) melakukan penelitian membahas pentingnya peran manajemen keragaman yang ditunjukan dalam konteks studi budaya Globe. Studi Globe menguji sembilan dari dimensi budaya dan pengaruh enam dimensi dari kepemimpinan dengan mengintergrasikan teori Hofstede, kebutuhan akan pencapaian McCelland dan dimensi budaya Inkeles dan Levinson. Hasil penelitian menunjukan praktek recruitmen yang memperhatikan keragaman signifikan diterapkan pada kepemimpinan berorientasi tim. Budaya kolektif berhubungan positif dengan kepemimpinan "humane". Kepemimpinan manusia yang memiliki perhatian, sensitivitas, unsur persahabatan dan dukungan bagi orang lain.

3. Manajemen Pengetahuan Dalam Perubahan

Perusahaan multinasional merupakan pemain utama dalam ekonomi global, kemampuan dalam menciptakan dan mentransfer pengetahuan merupakan salah satu keunggulan bersaing utama. Kompleksitas struktur organisasi dan proses manajemen di dalam perusahaan multinasional bertujuan meningkatkan keunggulan bersaing melalui stragegi integrasi global dan diferensiasi lokal (Pesalj, 2011). Jaringan yang memfasilitasi proses pengetahuan antara perusahan induk dan host country agar mampu diciptakan pengetahuan baru yang bersifat tacit yang sulit untuk ditiru.

Strategi bersaing utama yang dilakukan oleh perusahaan multinasional adalah aktif dalam mengupayakan pengembangan kemampuan organisasi dan peningkatan kapabilitas menciptakan inovasi dan menggunakan pengetahuan baru (Von Krogh et al., 2001). Hal ini juga sesuai dengan pendapat dari (Raudeliūnienè, Davidavičienè, \& Jakubavičius, 2018), dalam sebuah studi di perusahaan Korea menyimpulkan bahwa proses berbagi pengetahuan antar unit perusahaan berpengaruh secara positif terhadap kinerja perusahaan home country. Namun hasil penelitian lainnya menunjukan hal yang kontradiktif, (Qin et al., 2011) mengindikasikan adanya pengaruh negatif dari jarak budaya terhadap skema proses pengetahuan dalam organisasi. Temuan ini mengkonfirmasi temuan dari (Lin \& Wang, 2019) bahwa jarak budaya merupakan penghambat dari transfer pengetahuan, meskipun dari nilai budaya tertentu juga dapat memberikan pengaruh positif.

Perubahan agar berhasil diterima oleh semua pihak dalam organisasi maka pemimpin harus bersemangat dan terus menerus memberikan pemahaman tujuan dan urgensi kebutuhan bisa dipahami dengan jelas. Penolakan banyak terjadi dalam perubahan dikarenakan kesiapan dari pengikut atas kemampuan yang dimiliki berbeda dengan tuntutan peran di pekerjaan yang baru. Ketakutan bahwa beban kerja akan meningkat serta kecurigaan motif organisasi yang mungkin mempengaruhi financial atau status (Rao, 2015). Dari sisi organisasi untuk mempersiapkan karyawan dalam program pengembangan yang tepat harus dipersiapkan. 
Faktor pendorong pembelajaran dalam organisasi:

1. Pembelajaran organisasi merupakan tuntutan dan juga faktor pendorong ekternal dari pembelajaran. Pengetahuan advisor dari parent company sangat membantu peningkatan know how dan skill up.

2. Kesadaraan akan pengetahuan eksogen dari mitra organisasi dapat digunakan sebagai sumber pengetahuan baru yang penting.

3. Daya dukung organisasi dan daya dukung atasan yang memadai terutama dalam membantu memencahkan masalalah dalam pekerjaan.

4. Hubungan interpersonal dalam kelompok agar terjaga baik namun persaingan diantara anggota tidak bisa dihindari, malas bekerja sama dan berbagi pengetahuan dengan orang lain.

5. Skema pembelajaran organisasi dinilai belum tepat untuk mengembangkan kapasitas organisasi.

Studi-studi ini berkaitan dengan bagaimana anak perusahaan dapat berkontribusi pada keuntungan spesifik perusahaan dari MNC melalui penerimaan dan pemberian pengetahuan. Tetapi mereka tidak mengeksplorasi efek moderasi jarak budaya antara kantor pusat dan anak perusahaan pada aliran pengetahuan dalam perusahaan multinasional. Menurut (Qin et al., 2011) transfer pengetahuan dipengaruhi konteks eksternal dan mekanisme internal, dengan perbedaan budaya sebagai variable eksternal memiliki dampak terhadap efektifitas keberhasilan transfer pengetahuan.

Penelitian selanjutnya dari (Lucas, 2006) mengindikasikan perbedaan budaya dapat menciptakan hambatan atau menghilangkan potensi kesuksesan transfer pengetahuan. Kualitas hubungan antara anak perusahaan dan dengan kantor pusat memiliki implikasi besar untuk transfer pengetahuan. Transfer pengetahuan sebagai usaha berisiko dan tingkat kepercayaan tertentu harus ada di antara para pihak untuk "melakukan hal yang benar", bahkan jika melakukannya adalah atas perintah dari kantor pusat. Jika hubungan dianggap buruk, maka resistensi perubahan akan terjadi bahkan jika anak perusahaan menyadari bahwa mereka dapat mengambil manfaat dari pengetahuan transfer.

\section{Kesimpulan}

Tindakan top manajemen dalam membangun mental perubahan, penyampaian visi misi secara jelas, upaya keterbukaan komunikasi dengan manajemen lokal dapat mendukung keberhasilan perubahan. Dari penelitian ini dapat disimpulkan faktor yang memberikan kontribusi keberhasilan perubahan adalah komunikasi dalam unit organisasi, keterlibatan dari semua komponen termasuk peran top manajemen yang melakukan pesan berulang untuk mengkomunikasikan perubahan.

Budaya tidak ada yang salah, namun menyelaraskan budaya terhadap visi, misi dan strategi bisnis harus dapat dilakukan oleh pemimpin. Keselarasan dapat tercipta melalui peningkatan kapabilitas dari semua komponen organisasi. Budaya organisasi itu penting karena norma-norma membantu karyawan merasakan sesuatu kenyamanan selama perubahan. perusahaan multinasional kesuksesan mengelola keragaman adalah 
Faktor-Faktor Anteseden Perubahan Organisasi pada Perusahaan Multinasional

tugas penting dari pimpinan. Budaya kolektif berhubungan positif dengan kepemimpinan "humane". Kepemimpinan manusia yang memiliki perhatian, sensitivitas, unsur persahabatan dan dukungan bagi orang lain. 


\section{BIBLIOGRAFI}

Artina, Bella Santya, Desnasari, Dita, Fitriyah, Fita, \& Rizkita, Rainda Goesti. (2020). The Workforce In Indonesian Organizations: An Analysis Based Upon The Cultural Dimensions Of Hofstede's Model. Journal Of International Conference Proceedings (Jicp), 3(1), 56-64. Google Scholar

Ashta, Ashok, Stokes, Peter, \& Hughes, Paul. (2018). Change Management In IndoJapanese Cross-Cultural Collaborative Contexts. Journal Of Organizational Change Management. Google Scholar

Bojesson, Catarina, \& Fundin, Anders. (2020). Exploring Microfoundations Of Dynamic Capabilities-Challenges, Barriers And Enablers Of Organizational Change. Journal Of Organizational Change Management. Google Scholar

Chang, Chi Cheng, Yan, Chi Fang, \& Tseng, Ju Shih. (2012). Perceived Convenience In An Extended Technology Acceptance Model: Mobile Technology And English Learning For College Students. Australasian Journal Of Educational Technology, 28(5), 809-826. Google Scholar

Davis, Elizabeth B., Kee, James, \& Newcomer, Kathryn. (2010). Strategic Transformation Process: Toward Purpose, People, Process And Power. Organization Management Journal, 7(1), 66-80. Google Scholar

De Waal, Andre, \& Heijtel, Ivo. (2016). Searching For Effective Change Interventions For The Transformation Into A High Performance Organization. Management Research Review. Google Scholar

Duncan, Phyllis, \& Herrera, Richard. (2014). The Relationship Between Diversity And The Multidimensional Measure Of Leader-Member Exchange (Lmx-Mdm). Journal Of Management Policy And Practice, 15(1), 11. Google Scholar

Dzunic, Marija, Boljanovic, Jelena Djordjevic, \& Subotic, Jana. (2012). The Importance Of Concepts Of Knowledge Management And Learning Organization In Managing The Knowledge-Flow In Organizations. Management, Knowledge And Learning International Conference, 5. Google Scholar

Elenkov, Detelin S., \& Manev, Ivan M. (2009). Senior Expatriate Leadership's Effects On Innovation And The Role Of Cultural Intelligence. Journal Of World Business, 44(4), 357-369. Google Scholar

Geringer, J. Michael, \& Hebert, Louis. (1989). Control And Performance Of International Joint Ventures. Journal Of International Business Studies, 20(2), 235-254. Google Scholar

Hughes, Mark. (2011). Do 70 Per Cent Of All Organizational Change Initiatives Really Fail? Journal Of Change Management, 11(4), 451-464. Google Scholar 
Javidan, Mansour, \& Teagarden, Mary B. (2011). Conceptualizing And Measuring Global Mindset. In Advances In Global Leadership. Emerald Group Publishing Limited. Google Scholar

Krogh, Georg Von, Nonaka, Ikujiro, \& Aben, Manfred. (2001). Making The Most Of Your Company' S Knowledge: A Strategic Framework. 34, 421-439. Google Scholar

Kumar, Ravi, \& Singh, Vikrant. (2020). Impact Of Organisational Learning On Job Performance: A Study Of Education Sector. International Journal Of Knowledge Management And Practices, 8(1), 23. Google Scholar

Lin, Guangbo, \& Wang, Tienan. (2019). Research On The Influence Relationship Between Corporate Relationship Capital And Knowledge Transfer Effect. Panyapiwat Journal, 11(1), 155-168. Google Scholar

Lucas, Leyland M. (2006). The Role Of Culture On Knowledge Transfer: The Case Of The Multinational Corporation. The Learning Organization. Google Scholar

Mangundjaya, W. H. (2013). Organizational Commitment's Profile During The Transformation And Its Relation To Employee Commitment To Change.(A Study At Oil Company In Indonesia During Large-Scale Organizational Change). Proceeding Inbam Conference. Google Scholar

Manning, Mark, Shacklock, Arthur, Bell, Neville, \& Manning, Rana. (2012). Organizational Climate And Service Climate In Tourism And Hospitality: A Review. The Journal Of New Business Ideas \& Trends, 10(2), 1. Google Scholar

Pesalj, Biljana. (2011). Competitive Advantages Of Multinational Companies: A Review Of Theoretical Approaches. Medjunarodni Problemi, 63(2), 237-259. Google Scholar

Plowman, Donde Ashmos, Solansky, Stephanie, Beck, Tammy E., Baker, Lakami, Kulkarni, Mukta, \& Travis, Deandra Villarreal. (2007). The Role Of Leadership In Emergent, Self-Organization. The Leadership Quarterly, 18(4), 341-356. Google Scholar

Qin, Cindy, Ramburuth, Prem, \& Wang, Yue. (2011). A Conceptual Model Of Cultural Distance, Mnc Subsidiary Roles, And Knowledge Transfer In China-Based Subsidiaries. Organizations And Markets In Emerging Economies, 2(2), 8-27. Google Scholar

Rao, M. S. (2015). The Tools And Techniques Of Effective Change Management. Human Resource Management International Digest, 23(1), 35-37. Https://Doi.Org/10.1108/Hrmid-12-2014-0163. Google Scholar

Raudeliūnienè, Jurgita, Davidavičienè, Vida, \& Jakubavičius, Artūras. (2018). Knowledge Management Process Model. Entrepreneurship And Sustainability 
Issues, 5(3), 542-554. Google Scholar

Satsios, Nikolaos, \& Hadjidakis, Spyros. (2018). Applying The Theory Of Planned Behaviour (Tpb) In Saving Behaviour Of Pomak Households. International Journal Of Financial Research, 9(2), 122-133. Google Scholar

Tietze, Susanne. (2021). Cross-Cultural Management Revisited: A Qualitative Approach. Springer. Google Scholar

Vlajčić, Davor, Caputo, Andrea, Marzi, Giacomo, \& Dabić, Marina. (2019). Expatriates Managers' Cultural Intelligence As Promoter Of Knowledge Transfer In Multinational Companies. Journal Of Business Research, 94, 367-377. Google Scholar

Von Krogh, Georg, Nonaka, Ikujiro, \& Aben, Manfred. (2001). Making The Most Of Your Company's Knowledge: A Strategic Framework. Long Range Planning, 34(4), 421-439. Google Scholar

\section{Copyright holder:}

Yuanti Adi Hutami, Mirwan Surya Perdhana (2021)

First publication right:

Syntax Literate: Jurnal Ilmiah Indonesia

This article is licensed under: 